American Journal of Pharmaceutical Education 2019; 83 (3) Article 6597.

\title{
RESEARCH
}

\section{Perceptions of Australian and Malaysian Educators in an Undergraduate Pharmacy Program on Case-based Learning}

\author{
Sabrina Anne Jacob, PhD, MPharm, BPharm (Hons), ${ }^{\text {a,b }}$ Ong Hui Dhing, BPharm (Hons), \\ Daniel Malone, PhD, BPharm (Hons) ${ }^{\mathrm{C}}$ \\ ${ }^{a}$ School of Pharmacy, Monash University Malaysia, Selangor, Malaysia \\ ${ }^{\mathrm{b}}$ Strathclyde Institute of Pharmacy and Biomedical Sciences, University of Strathclyde, Glasgow, United Kingdom \\ ${ }^{\mathrm{c}}$ Faculty of Pharmacy and Pharmaceutical Sciences, Monash University, Parkville, Australia
}

Submitted June 19, 2017; accepted September 20, 2017; published April 2019.

Objective. To determine the perceptions of lecturers toward case-based learning (CBL) and to elicit their feedback and opinions regarding the design of CBL sessions within the pharmacy curricula.

Methods. One-on-one interviews were conducted with 10 academic staff members involved in teaching an undergraduate Bachelor of Pharmacy (BPharm) program. All sessions were audio-recorded and field notes were compiled. The recordings were transcribed, and thematic analysis of responses was performed. Results. Four key themes were identified: perceived benefits of CBL, challenges in implementing CBL within the curricula, characteristics of effective and engaging CBL, and relevance and implementation of CBL within the curriculum. Some of the specific benefits of CBL identified by participants included the applicability of knowledge learned to students' future role as pharmacists. Participants also identified challenges such as the design of CBL cases and course time constraints. Respondents also emphasized the need for more training for facilitators in how to design cases and facilitate sessions.

Conclusion. While participants identified numerous benefits of CBL, they also identified challenges to implementing this learning method within the pharmacy school curriculum. Paying careful attention to selecting facilitators and providing appropriate facilitator training, in terms of facilitation and case design, is paramount in effectively implementing CBL sessions.

Keywords: case-based learning; pharmacy education; undergraduate education; facilitators; problem-based learning

\section{INTRODUCTION}

The teaching and training of future health professionals have evolved in an atmosphere of increasing demand for better quality courses and highly skilled graduates. Educators are aware that passive acquisition and reproduction of examination-directed information from traditionally one-way, didactic teaching fails to develop students' full potential. ${ }^{1}$ In addition, the amount of time available to teach students the growing body of pharmacy knowledge is limited. ${ }^{2,3}$ Thus, to maintain accountability to society and advance the profession, the paradigm in pharmacy education has shifted from traditional, inputbased teaching to a greater focus on learner outcomes. ${ }^{4}$

Contemporary pharmacy practice demands that graduates be able to respond to evolving professional challenges, collaborate effectively within interprofes-

Corresponding Author: Sabrina Anne Jacob, Strathclyde Institute of Pharmacy \& Biomedical Sciences, University of Strathclyde, 161 Cathedral St, Glasgow G4 0RE, Scotland. E-mail: sabrina.jacob@strath.ac.uk sional teams, and develop further through lifelong learning to enhance patient and population outcomes. ${ }^{5,6}$ To this end, the International Pharmaceutical Federation recommends that active-learning (AL) strategies be employed in higher education. ${ }^{7}$ The most used strategy among pharmacy schools in the United States is problem-based learning (PBL), which includes case-based learning (CBL) ${ }^{1}$ and is increasingly being adopted around the world.

Both PBL and CBL have advantages over lecturebased teaching, such as students being actively engaged and focused on higher-order learning. ${ }^{8}$ However, apart from being relatively resource- and staff-intensive, the lack of faculty control and structure may account for some hesitancy on the part of pharmacy schools to adopt PBL. ${ }^{9}$ Indeed, in a curricular shift from PBL to CBL involving second- and third-year medical students, the students preferred the latter, claiming it provided more opportunities for the application of clinical skills. ${ }^{10}$

From the point of view of learners, CBL is essentially student-centred because of the many benefits 


\section{American Journal of Pharmaceutical Education 2019; 83 (3) Article 6597.}

reported, such as enabling a deep and AL state to occur, ${ }^{11,12}$ developing clinical competencies and professional attributes for future practice, ${ }^{13,14}$ fostering communication skills and teamwork, ${ }^{15}$ and motivating independent learning. ${ }^{12}$ While PBL can be described as a type of open inquiry that relies on students to generate issues and learning points from the case, with minimal facilitator interference or need for prior knowledge, ${ }^{16}$ $\mathrm{CBL}$ is more structured. In CBL there is more guidance from a content expert as students analyse a situation in small groups using previously acquired knowledge and various resources and then present possible solutions to the class. ${ }^{10,17}$

The role of the facilitator in CBL has been identified by students as paramount in optimizing learning gains. In a pilot study by Jacob and colleagues, pharmacy students perceived that facilitators should be engaging and actively participate as part of a dynamic process, continuously providing feedback. ${ }^{18}$ Indeed, the role of the course facilitator, in managing group dynamics, ensuring a balance of participation, and navigating the breadth of discussions, has an impact on healthcare students' satisfaction with the course. ${ }^{19}$ However, while faculty members appreciate CBL for its benefits in student learning and interaction, ${ }^{20,21}$ implementation can be challenging compared to lecture-based teaching. In an undergraduate surgical curriculum where CBL was implemented with little success, faculty members found mastering the necessary skills to be effective facilitators in the classroom to be challenging, and thus felt like novices instead of experts in their role. ${ }^{22}$ Although many articles have been written about $\mathrm{CBL}$, the perspectives of lecturers on CBL in undergraduate pharmacy have yet to be explicitly and qualitatively explored.

From 2012 to 2016, there has been a fundamental change in how teaching in an undergraduate pharmacy program is implemented at a public Australian university that has a campus in Malaysia, from mostly lecturebased teaching strategies to a much greater emphasis on AL teaching strategies. ${ }^{23}$ The current curriculum uses an integrative approach, in which science-based topics and practice-based topics are covered within the same unit. (A unit is normally a semester-long component, and four units are normally taught concurrently and comprise a semester of teaching.) The increase in AL in teaching both large and small classes has involved a greater focus on CBL. Because lecturers are currently and will continue to be on the frontlines of designing and carrying out this teaching/learning method, the primary aim of this qualitative study was to determine the perceptions of lecturers toward CBL. A secondary objective was to elicit their feedback and opinions regarding the design of CBL sessions within the pharmacy curricula. A qualitative design was employed as it allowed respondents to fully express themselves and give responses beyond the options provided on quantitative questionnaires.

\section{METHODS}

Purposive sampling was used whereby academic staff members who were involved in teaching undergraduate pharmacy students and had a good command of English were recruited to participate in the study. An invitation letter explaining the study was sent to prospective subjects via email. Interviewees were informed that their responses would be anonymized and audio recorded. An interview guide was developed based on the study objectives and a review of the literature (Appendix 1). Face and content validation was done by experts in qualitative research, and academics involved in undergraduate pharmacy and medical teaching, who were not involved in the study.

Qualitative, one-on-one interview sessions were conducted. Two of the authors conducted the interviews in private to ensure confidentiality, and at a time convenient to the study participants. Each interview session lasted from 30 minutes to one hour. During each session, the interviewer took field notes to capture key points. Participants were asked to provide relevant demographic information via email.

Recorded interviews were transcribed verbatim and deidentified prior to analysis. Results were then imported into NVivo 11 software (QSR International, Melbourne, Victoria). All audio-recordings and interviewer field notes were also imported into NVivo for comparison and analysis. Thematic analysis was performed on the transcripts by two researchers guided by Braun and Clarke's six phase approach to coding. ${ }^{24}$ Any discrepancies between the researchers' findings were resolved by consensus. Respondents' comments were edited on a limited basis to remove content that did not convey meaning (repeated words, stutters, etc) and to correct grammar. An ellipsis was used to note removal of such extraneous content. Square brackets were used in quotations to supply words omitted by the speaker or to replace sensitive information where names were mentioned. The research protocol was reviewed and approved by the Monash University $\mathrm{Hu}-$ man Research Ethics Committee.

\section{RESULTS}

Ten academic teaching staff members agreed to participate in the study. There was a slight preponderance $(60 \%)$ of female participants. Participants ranged in age from 34 to 53 years. Two respondents were involved in 


\section{American Journal of Pharmaceutical Education 2019; 83 (3) Article 6597.}

pharmacy practice, while the rest taught basic science courses. Other demographic characteristics of respondents are presented in Table 1. Qualitative analysis revealed two themes, each of which concerned participants' perceptions of CBL and CBL design. These are summarized below and in Table 2 .

\section{Perception of CBL}

The first theme identified from our analysis of the interviews was "Perceived benefits of CBL." Under the subtheme of "Knowledge transfer," respondents felt that CBL helps in translating complex, technical, and abstract concepts into concrete and/or meaningful information and allowed students to engage with theories and concepts at a deeper level or from a different perspective. This was especially relevant in science and nonclinical subjects as lecturers perceived these types of content as difficult to teach and somewhat inaccessible to students. Specifically, respondents felt that putting highly scientific and technical definitions into the context of a case helped students understand the material better. The participants also perceived CBL to be a way for students to check if they had all of the correct information and had understood the concepts that had been discussed during lectures.

Respondents saw the application of knowledge and skills in a particular scenario as a means to enable stimulation or thinking on a wider plane, as well as to trigger higher-order skills such as critical thinking, problemsolving, logic, and reasoning. As noted, respondents believed that CBL enhances student learning because of the deeper analysis and discussion that it involved. Participants thought that traditional lectures led to superficial understanding and short-term memory retention. Thus, they believed that putting things in a clinical context by using examples in the form of cases would aid students in understanding and remembering what had been taught. Science-based lecturers also found that CBL helped students remember technical concepts and theories taught during class.

Participants noted that having students work in groups during CBL was essential to helping them develop skills in working as part of a team, as well as an appreciation for the value of considering different perspectives when reviewing the elements of a case. The faculty members believed this exposure to different thought processes and opinions contributed to students' overall development. This translated to students learning from their peers through these interactions, as participants believed that students' discussions with friends helped improve their understanding of a particular topic. Establishing this rapport was thought to provide a platform for students to grade and assess one another as part
Table 1. Demographic Characteristics of Pharmacy Educators Interview Participants

\begin{tabular}{|c|c|}
\hline Characteristics & $\begin{array}{c}\text { No. of } \\
\text { Respondents }\end{array}$ \\
\hline Age, Mean $(\mathrm{SD})^{\mathrm{a}}$ & $40(5)$ \\
\hline \multicolumn{2}{|c|}{$\begin{array}{l}\text { Number of years teaching undergraduate } \\
\text { pharmacy* }\end{array}$} \\
\hline$<5$ years & 0 \\
\hline $5-10$ years & 1 \\
\hline$>10$ years & 8 \\
\hline \multicolumn{2}{|c|}{ Area of specialization in teaching ${ }^{\mathrm{a}, \mathrm{b}}$} \\
\hline Pharmacy practice & 2 \\
\hline Pharmacology & 4 \\
\hline Drug delivery & 2 \\
\hline Molecular biology & 1 \\
\hline Medicinal chemistry & 2 \\
\hline \multicolumn{2}{|l|}{ Degree $^{c}$} \\
\hline BPharm & 5 \\
\hline $\mathrm{BSc}$ & 5 \\
\hline $\mathrm{MSc}$ & 1 \\
\hline MClinical Pharm & 1 \\
\hline MPharm & 2 \\
\hline $\mathrm{PhD}$ & 9 \\
\hline \multicolumn{2}{|c|}{$\begin{array}{l}\text { a One respondent declined to provide demographic details } \\
{ }^{b} \text { Numbers might total more than } 9 / 10 \text { as respondents were allowed to } \\
\text { select more than one option } \\
{ }^{c} \text { BPharm=Bachelor of Pharmacy, BSc=Bachelor of Science, } \\
\text { MSc=Master of Science, MClinical Pharm = Masters in Clinical } \\
\text { Pharmacy, MPharm=Masters of Pharmacy (undergraduate), } \\
\text { PhD=Doctor of Philosophy }\end{array}$} \\
\hline
\end{tabular}

of working in a group to ensure teammates were progressing well.

In terms of "Application to future roles," respondents felt that given that students were not exposed to real-life situations during their pre-university days, contextualizing cases according to real-life scenarios would help students learn better as it enabled them to see how information they learned would be useful in their future roles as pharmacists. Respondents also felt it helped students understand that healthcare does not happen in a vacuum and is influenced by other determinants of health, such as social, ethical, and economic factors. Exposing students to real-world situations through cases would also serve to mature and develop students overall. Respondents also believed that the analysis of real-life cases allowed students to begin to consolidate their skillsets for specific professional competencies like counselling and providing pharmaceutical care to patients.

The second theme, "Issues within the curriculum," encompassed the challenges of implementing CBL within the curriculum. Respondents believed setting up the CBL sessions would be fairly work intensive. Existing modes 
American Journal of Pharmaceutical Education 2019; 83 (3) Article 6597.

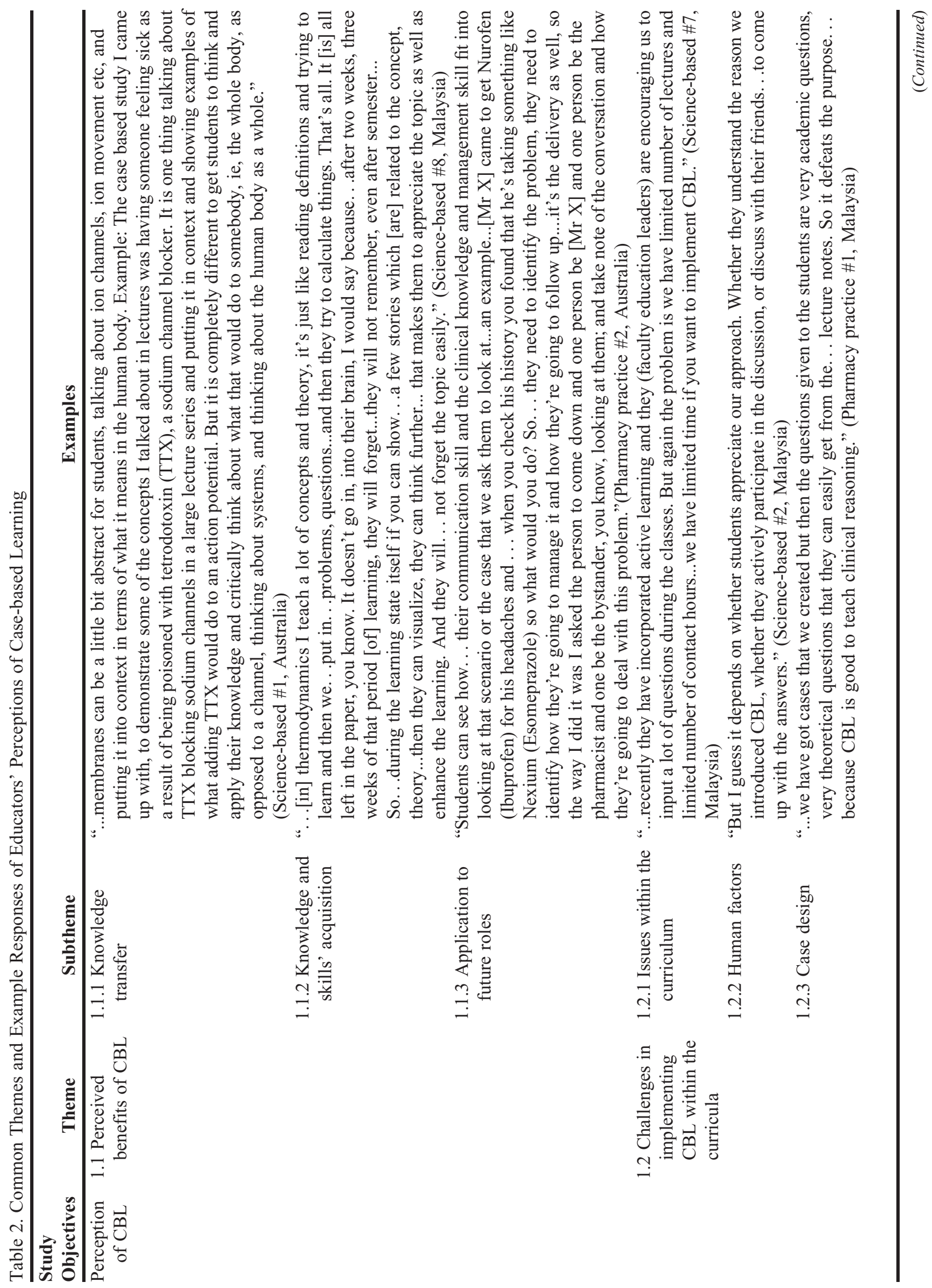


American Journal of Pharmaceutical Education 2019; 83 (3) Article 6597.

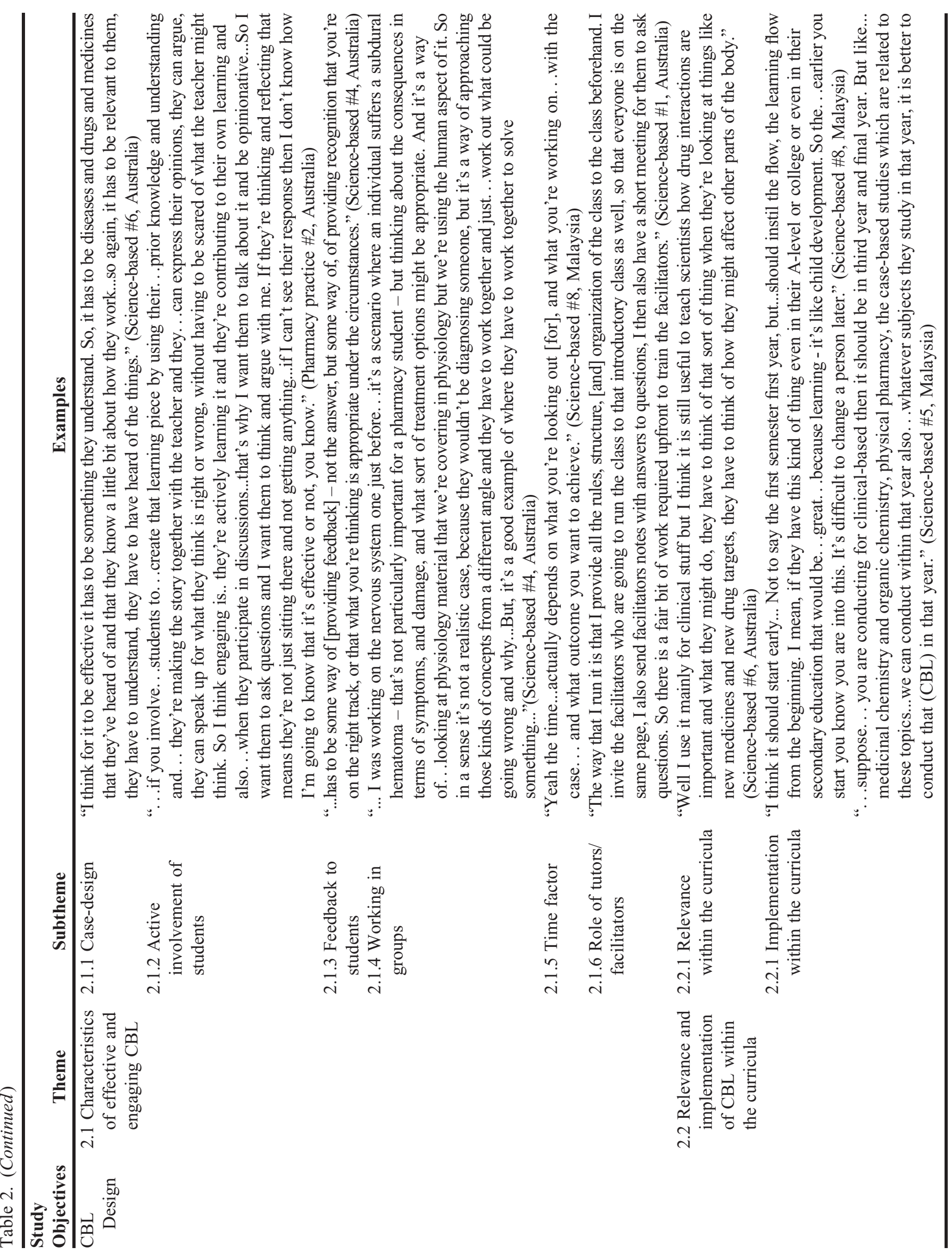




\section{American Journal of Pharmaceutical Education 2019; 83 (3) Article 6597.}

of learning, such as AL and online wikis, that would play a role in the mode of delivery of CBL sessions, also needed fine-tuning. Case-based learning was also not part of the course or unit guide at the time of the study and was therefore not formally timetabled (ie, no specific time slot was allocated for it). This led to time constraints to conduct these sessions within current lecture or tutorial sessions in a curriculum that was already overloaded.

With regard to "Human factors," the participants noted that one of the challenges would be getting facilitators who were enthusiastic and engaging to run the sessions, and then training them to facilitate rather than just tutor. One respondent also pointed out that the success of implementing CBL was dependent on the attitude of students, who preferred to adopt passive roles during classes and did not seem to like AL. A further challenge was trying to get students to work in groups rather than taking the information and trying to solve the problem on their own.

Case design was an important subtheme, with seven respondents stating that designing cases would be the biggest challenge to implementing CBL and would require a significant amount of skills and time. Some of the specific challenges that participants noted were designing cases that were logical, realistic, and challenging, and could be used in different situations to explain different concepts without being too difficult. Other challenges that participants noted were making the cases relevant, being able to articulate to students why the case was relevant, and linking the cases to the course content as well as to assessments. Participants explained that the cases they were using were continuously recycled, and the accompanying questions were often theoretical, which impeded learning. Several of the science-based lecturers lamented that not all of the topics they taught, such as physical and organic chemistry, could be converted into cases, and could be taught better through practical classes (eg, laboratory classes).

\section{CBL Design}

With regard to the theme "Characteristics of effective and engaging CBL," respondents were unanimous in their opinion that the most important element to ensure effective CBL sessions was the design of good cases, with one suggesting using live patients and creating videos. The importance of first outlining learning objectives and the intended outcomes was imperative in deciding whether cases were indeed suitable for CBL. Among the suggestions were that cases should be logical, directly related to the lecture series, and accompanied by insightful questions that actually make students think. The respondents believed that cases should be simple, but not so simple that students could solve it on their own (for cases where students were expected to work in groups). Also, the cases should not be so challenging that some students would feel they could not contribute. Respondents also noted that there was an expectation by students that the cases should be connected to their assignments and assessments. One respondent suggested that cases should be dramatic in order to pique the interest of students, while others suggested that in order to be effective, the students should have already completed background material on the topic covered in the case prior to class.

Another key characteristic noted for effective CBL sessions was for students to be actively involved, engage in debates and discussions, be able to justify case management decisions, and be able to present information to the rest of the group. This would also assist facilitators in discerning whether students have a good grasp of the content. Students should also be active agents in their own learning and be prepared to be "put on the spot" during class. So to fully benefit from each session, it was important for students to come prepared, having read the assigned course materials.

Respondents felt it was equally important for the course facilitator to give feedback to the students. This was based on comments faculty members had received from students who felt facilitator feedback had helped them know whether they were progressing well. Group work was also stressed here as it encouraged students to work as a team, and support one another in solving a case. Respondents agreed that groups should be no larger than four or five students, as having more could lead to only a few students actively engaging in discussion while others were either left out or did not see the need to participate. While most respondents felt that CBL sessions should be no longer than one hour to prevent students from becoming disengaged, one respondent suggested that the length of each session should be based instead on the objectives to be covered.

All respondents stressed the importance of having properly trained facilitators to ensure the success of CBL sessions. They also emphasized the need for facilitators to go beyond teaching to facilitating instead, which the respondents perceived as more difficult. Respondents noted that facilitators should not adopt a passive role in the classroom, but instead should draw the students into the cases. Also, facilitators should play an active role in the revision of cases prior to class to make it easier for students to comprehend the sessions. Most respondents preferred that facilitators conduct the CBL sessions as they were the content experts and would be cognizant of the degree to which they should be involved in a 


\section{American Journal of Pharmaceutical Education 2019; 83 (3) Article 6597.}

session, ie, when to guide the students and when to step back. Respondents also felt that faculty members would require training before assuming this role, as a different set of skills is required to conduct and facilitate CBL sessions. Some noted that students were capable of asking unexpected questions, and the facilitator's expertise would be helpful in this regard. The respondents recommended that a guide be prepared for facilitators to help them prepare for these and other unexpected situations.

Under the second theme of "Relevance and implementation of CBL within the curricula," nine respondents felt that while mandatory for clinical topics, CBL was applicable to both clinical and science-based topics. There were concerns, however, as to whether a case would be able to stand alone for science-based topics, with respondents suggesting integration with other topics within units. For example, elements of management could be integrated into pharmacology and chemistry cases. Respondents were unanimous that CBL should be initiated in the first year of the pharmacy program, and that a scaffolded approach should be used so that the complexity of the cases increases as students progress through the course. In the same vein, detailed instructions and guidance should be provided to students upon implementation to orientate students to the expectations and intended outcomes for CBL so that they would know what was expected of them, how to approach a CBL session, and what resources they needed to look at to prepare. This preparation would encourage their involvement in the sessions.

The respondents believed the type of topics covered should be dependent on the year of study, with cases tailored to the subject matter being taught in the respective years. Indeed, how a case is designed and the intended purpose for clinical topics differs between science- and clinical-based topics. For instance, in pharmacology, the emphasis is not so much on managing a patient or disease as it is about drugs and their mechanisms of action. Another suggestion was to apply the same structure or format to facilitate learning in both science-based and therapeutic units across the years.

\section{DISCUSSION}

The aim of this study was to gain insight into the perceptions about CBL of lecturers who teach an undergraduate pharmacy curriculum, for the purpose of using this information to better construct and run CBL classes. Respondents agreed that CBL is a useful means by which to apply knowledge and develop skills such as communication, problem-solving, and teamwork. ${ }^{15}$ The majority of those interviewed also appreciated the relevance of $\mathrm{CBL}$ in the context of the future roles of students as pharmacists. This is in agreement with the concept that CBL is a constructivist model that enhances problem-solving abilities, relates course material directly to practical outcomes, ${ }^{25}$ and aids in the development of professional skills. ${ }^{13,14}$

We were encouraged to learn that all of the sciencebased respondents currently used some format of CBL within their units and were cognizant of the role of CBL in facilitating students' undestanding of technical scientific concepts. This is a departure from a 2011 survey which found that pharmacy practice staff members were three times more likely to use AL strategies compared with science- and pharmaceutical-based staff members. ${ }^{2}$ This shift might signal the advent of more science-based faculty members adapting CBL components within their units, given the importance of future pharmacists being able to apply their knowledge and think critically when managing patients--skills that are not effectively imparted through lecture-based teaching. ${ }^{1}$

While CBL is more easily translatable to clinicaltype subjects, there was a general perception that CBL helped to develop relevance of material, particularly in basic science-type subjects such as chemistry and pharmacology. This is in agreement with a number of studies that have promoted the benefits of teaching basic science subjects in a CBL format. ${ }^{15,25-27}$ In a toxicology elective in which students met once a week for two hours and worked on case-based problems for an hour, examination scores improved. The CBL component also provided a clinically relevant experience in which students actively engaged with the material. ${ }^{27}$

Science-based respondents in our study did lament the fact that it was challenging to develop cases for science-based material, and that science-based subjects could not stand alone without clinical topics when conducting CBL sessions. Thus, these respondents proposed that there should be an integration of science and clinical material within cases. As reported in a 2010 study, this approach was taken to teach undergraduate pharmacy students about osteoarthritis and rheumatoid arthritis, where students were required to apply their knowledge of all course components to successfully manage the patient. At the end of the study, students displayed mastery over course material and rated this format highly on the course evaluation. $^{28}$

Educators should also make an allowance for the fact that any one format or pedagogy might not suit all units. Indeed, science-based learning might require different methods of thinking and processes of learning which in turn might require a different method of teaching. While integration of material might work, it might be more practical to simply use different AL pedagogies for science and practice material. One such pedagogy is the Process 


\section{American Journal of Pharmaceutical Education 2019; 83 (3) Article 6597.}

Oriented Guided Inquiry Learning (POGIL), which uses guided inquiry and has been found to increase students' problem-solving, critical-thinking, and communication skills. Students work in small groups, are assigned different roles, and are guided by a facilitator. However, POGIL focuses more on specific concepts in learning and the development of process skills, which may make it more useful in learning science-based topics. ${ }^{29,30}$ There is also a move to hybridize different pedagogies to optimize the benefits of each. ${ }^{29}$ Thus, in programs that strongly emphasize both science and clinical skills, adapting a hybrid of CBL and POGIL might be worth exploring.

Participants identified that conducting sessions in groups can assist in developing students' teamwork skills, increasing their appreciation of others' perspectives regarding a particular problem, and improving their understanding of a topic. ${ }^{20}$ Most higher education pedagogies subscribe to the concept of social constructivism, which implies that the process of building knowledge is aided through cooperative social interactions. ${ }^{29}$ Working in groups facilitates this and closely mirrors real world situations, thereby assisting students in building interprofessional relationships. ${ }^{31}$ This was reflected in a study involving students in a PharmD program who were tasked with working in small groups to communicate with simulated patients and design appropriate treatment and follow-up plans. Students felt the format provided significant opportunities to improve their verbal and written communication skills, problem-solving skills, and ability to work as part of a team. ${ }^{32}$ Although one of the challenges to group work that the respondents in our study highlighted was students' dislike of this format, other studies have found that students rated working in groups favorably, claiming it gave them greater satisfaction and that they valued being an active part of a group and sharing information. ${ }^{19,33}$

Another important aspect of group work is peer assessment, which allows for evaluation of non-content skills not usually assessed in traditional forms of assessment. ${ }^{34}$ Students have expressed the view that peer assessments helped develop their confidence, motivation, critical thinking, and team-building skills; made them more reflective, analytical, and self-aware; and provided another avenue for feedback. ${ }^{31,35,36}$ In another study, facilitators noted that intergroup peer assessment was effective in getting students more actively involved and in piquing students' interest. The students commented that they valued the feedback received from peers as it was different from that received from facilitators, and was more relatable as their peers had researched the same information as the students they were assessing. ${ }^{31}$ Students also felt it was easier to accept criticism from their peers as opposed to their facilitators. ${ }^{37}$ Peer-assessment, however, has led to students grading their peers too leniently. ${ }^{38}$ Some students also feel peer assessment is too challenging and time-consuming and therefore should be used in moderation and with proper guidance. ${ }^{39}$

Respondents were unanimous in their opinion that facilitators should assume an active role in CBL and direct student discussions, thus functioning as part of the group instead of as an observer. These discussions would serve to assist students' understanding of their expectations and standards, as well as to correct any misunderstandings. ${ }^{37}$ Indeed, the role of facilitators was seen as vital in encouraging group organization and equal contribution from members and was key to effective AL sessions. ${ }^{18,40-44}$ In the traditional system, feedback from facilitators was largely unidirectional, with facilitators telling students what they did right or wrong and the students using this information to make the necessary corrections. ${ }^{37}$ This is in contrast to the principles of CBL, which subscribes to the philosophy of students as self-regulated learners. Along with this change in teaching, there also should be a shift in the way feedback is given, or rather, the role that feedback plays. Indeed, the method of feedback in the current pedagogy has evolved as it is within an avenue where students are actively structuring their own knowledge and skill, and should instead be used to empower students to self-regulate their learning. Thus, feedback should be dialogical as opposed to transmission-centered, and students must interact actively with the feedback received in order for it to be effective. ${ }^{37}$

In the traditional transmission-centered feedback, the onus is solely on facilitators to provide feedback, thereby increasing their workload. To overcome this, facilitators can use peer assessment as an added source of feedback for students. ${ }^{31}$ Facilitators should also empower students to be more self-regulated and develop their selfassessment skills, as this will lead to them being less dependent on teachers. Indeed, studies have shown that students do generate their own feedback within CBL sessions, making the role of the facilitator simply to enhance this skill. ${ }^{37}$ Two examples of ways to overcome the difficulty of providing individual feedback to students given time constraints and large class sizes are using classroom technologies to trigger peer discussion, ${ }^{45,46}$ and having students write one-minute papers in class, which allow for rapid feedback. ${ }^{37}$

Our respondents also stressed the need for facilitators to be content experts. In previous studies, students have commented that having facilitators in the classroom who were not content experts was akin to the "uninformed leading the ignorant." ${ }^{19,44}$ Indeed, beyond being able to effectively direct discussions and recognize errors in 


\section{American Journal of Pharmaceutical Education 2019; 83 (3) Article 6597.}

comprehension, a content expert would be cognizant of the appropriate time they should spend and the extent to which they should intervene in student learning without compromising the tenets of self-regulated learning. ${ }^{47}$

Facilitators themselves have expressed that not being content experts affected their performance during $\mathrm{AL}$ sessions. ${ }^{44}$ However, because of budget constraints and staffing issues, getting content experts may not always be possible. A solution to this could be for facilitators to use Objective Structured Brainstorming Questions, a road map to guide nonexperts in effectively directing discussion sessions and ensuring students explore cases in a comprehensive manner. ${ }^{48}$ There is, however, some ambiguity with regard to the importance of content experts, with some finding it more of a hindrance in self-regulated learning, commenting that content experts would feel compelled to lecture. ${ }^{49}$

Facilitators have lamented that a key problem with facilitation was not knowing when to direct or when to facilitate in order to strike a balance between teaching students and guiding students to self-regulate. ${ }^{47}$ This aligns with the comment by our respondents and authors of other studies on the need for facilitators to be appropriately trained. ${ }^{18,44,49}$ This was identified as being important to ensure consistency across multiple classes being run by different facilitators, as well as adapting facilitators with the specific skills required to facilitate CBL sessions. ${ }^{50}$

Some facilitators, however, are resistant to change as they are more familiar with the traditional role of teachers. ${ }^{51}$ Of particular concern are the subversive facilitators who do not believe in the philosophy of CBL and $\mathrm{AL}$, and who might subtly or overtly communicate to students that they are receiving lower quality education. ${ }^{49}$ Students themselves have noted that facilitators who did not support PBL performed worse as facilitators. ${ }^{44}$ Thus, facilitator training needs to include a reflection on what or how they feel about the philosophy behind CBL and AL to ensure that they are indeed aligned with the theory underpinning these teaching methods.

There was an overall acknowledgement by respondents that writing real-life cases is time consuming and requires significant training to be abe to create a case at the right learning level in terms of difficulty. An attempt to address how difficult cases should be for novice, intermediate, and advanced pharmacy students was developed by Spark and colleagues by altering a case difficulty cube originally developed for business students. ${ }^{52}$ This involved analyzing cases based on three dimensions (analytical, conceptual, and presentation) and recommending case-level difficulty based on these dimensions to be scaffolded through pharmacy courses. ${ }^{53}$ There also seems to be difficulty in adopting CBL due to time constraints within the current curriculum. One method of addressing this would be to use online CBL, where students attempt to complete the cases online in groups, and then the facilitator uses the results to facilitate in-class discussions with students. ${ }^{54}$ However, assuming that AL can be introduced successfully without first having to make structural changes to the curriculum would be naive. ${ }^{55}$

Only two respondents were specialists in pharmacy practice, while the other eight were science-based. However, this allowed us to gain an interesting perspective into CBL in terms of teaching a pharmacy course. In addition, while the sample size of 10 was small, eight respondents had more than 10 years' experience in teaching undergraduate pharmacy students. The use of two interviewers increased the potential for interrater reliability issues. Finally, the thematic analysis was done by one of the researchers, which may have introduced bias into the analysis.

\section{CONCLUSION}

Through interviews with science and pharmacy practice faculty members, this study identified several key benefits of CBL including student knowledge and skills acquisition, and application of concepts learned to future roles. Challenges identified included time required to design cases and appropriate training of facilitators to deliver CBL effectively. To ensure effective implementation of CBL sessions, careful attention should be paid to selecting facilitators and providing appropriate training for them, and designing the sessions taking into account case design issues and time constraints. Finally, for expanded implementation of CBL in the pharmacy curriculum, a shift is needed in facilitators' and students' perceptions of the role of facilitators.

\section{ACKNOWLEDGMENTS}

The authors would like to thank Associate Professor Somaiya Naidu for his assistance in the conception of the study, and all academic teaching staff who gave their time to take part in this study.

\section{REFERENCES}

1. Gleason BL, Peeters MJ, Resman-Targoff BH, et al. An activelearning strategies primer for achieving ability-based educational outcomes. Am J Pharm Educ. 2011;75(9):Article 186.

2. Stewart PDW, Brown SD, Clavier CW, Wyatt J. Active-learning processes used in us pharmacy education. Am J Pharm Educ. 2011;75(4):Article 68.

3. Garvey MT, O' Sullivan M, Blake M. Multidisciplinary casebased learning for undergraduate students. Eur J Dent Educ. 2000;4(4):165-168.

4. Nash RE, Chalmers L, Brown N, Jackson S, Peterson G. An international review of the use of competency standards in undergraduate pharmacy education. Pharmacy Education. 2015;15. 


\section{American Journal of Pharmaceutical Education 2019; 83 (3) Article 6597.}

5. Jungnickel PW, Kelley KW, Hammer DP, Haines ST, Marlowe $\mathrm{KF}$. Addressing competencies for the future in the professional curriculum. Am J Pharm Educ. 2009;73(8):Article 156.

6. Australian Pharmacy Council Ltd. Accreditation standards for pharmacy programs in Australia and New Zealand. In: Ltd APC, ed. Canberra 2012.

7. FIP Pharmacy Education Taskforce. A global framework for quality assurance of pharmacy education. The Hague: International Pharmaceutical Federation; 2008.

8. Dupuis RE, Persky AM. Use of case-based learning in a clinical pharmacokinetics course. Am J Pharm Educ. 2008;72(2):Article 29. 9. Lubawy W, Brandt B. A variable structure, less resource intensive modification of problem-based learning for pharmacology instruction to health science students. Naunyn-Schmiedeberg's Archives of Pharmacology. 2002;366(1):48-57.

10. Srinivasan M, Wilkes M, Stevenson F, Nguyen T, Slavin S. Comparing problem-based learning with case-based learning: effects of a major curricular shift at two institutions. Acad Med. 2007; 82(1):74-82.

11. Harman T, Bertrand B, Greer A, et al. Case-based learning facilitates critical thinking in undergraduate nutrition education: students describe the big picture. J Acad Nutr Diet. 2015; 115(3):378-388.

12. Hofsten A, Gustafsson C, Haggstrom E. Case seminars open doors to deeper understanding - nursing students' experiences of learning. Nurse Educ Today. 2010;30(6):533-538.

13. Kantar LD, Massouh A. Case-based learning: what traditional curricula fail to teach. Nurse Educ Today. 2015;35(8):e8-14.

14. Thomas MD, O'Connor FW, Albert ML, Boutain D, Brandt PA. Case-based teaching and learning experiences. Issues Ment Health Nurs. 2001;22(5):517-531.

15. Currie BL, Chapman RL, Christoff JJ, Sikorski L. Patient related case studies in medicinal chemistry. Am J Pharm Educ. 1994;

58(4):446-450.

16. Srinivasan M, Wilkes M, Stevenson F, Nguyen T, Slavin S. Comparing problem-based learning with case-based learning: Effects of a major curricular shift at two institutions. Acad Med. 2007; 82(1):74-82.

17. Tarnvik A. Revival of the case method: a way to retain studentcentered learning in a post-pbl era. Med Teach. 2007;29(1):e32-e36. 18. Jacob SA, Khan TM, Pusparajah P, Velu SS, Lee LH, Davey TM. Students' perceived predictors of an effective active learning/ problem-based learning session: a pilot study. J Pharm Prac Res. 2016;46(1):42-46.

19. Kilgour JM, Grundy L, Monrouxe LV. A rapid review of the factors affecting healthcare students' satisfaction with small-group, active learning methods. Teach Learn Med. 2016;28(1):15-25.

20. Thistlethwaite JE, Davies D, Ekeocha S, et al. The effectiveness of case-based learning in health professional education. A beme systematic review: beme guide no. 23 . Med Teach. 2012;34(6):e421-444.

21. Gade S, Chari S. Case-based learning in endocrine physiology: an approach toward self-directed learning and the development of soft skills in medical students. American Journal of

Physiology - Advances in Physiology Education.

2013;37(4):356-360.

22. Nordquist J, Sundberg K, Johansson L, Sandelin K, Nordenstrom J. Case-based learning in surgery: lessons learned. World J Surg. 2012;36(5):945-955.

23. White PJ, Larson I, Styles K, et al. Adopting an active learning approach to teaching in a research-intensive higher education context transformed staff teaching attitudes and behaviours. Higher Education Research \& Development. 2016;35(3):619-633.

24. Braun V, Clarke V. Using thematic analysis in psychology. Qualitative Research in Psychology. 2006;3(2):77-101.

25. Hartfield PJ. Reinforcing constructivist teaching in advanced level biochemistry through the introduction of case-based learning activities. Journal of Learning Design 2010;3(3):12.

26. Vora MB, Shah CJ. Case-based learning in pharmacology: moving from teaching to learning. International Journal of Applied and Basic Medical Research. 2015;5(Suppl 1):S21-S23.

27. Brown SD, Pond BB, Creekmore KA. A case-based toxicology elective course to enhance student learning in pharmacotherapy. Am J Pharm Educ. 2011;75(6):Article 118.

28. Marshall LLP, Nykamp DP. Active-learning assignments to integrate basic science and clinical course material. Am J Pharm Educ. 2010;74(7):Article 119.

29. Eberlein T, Kampmeier J, Minderhout V, et al. Pedagogies of engagement in science. Biochem Mol Biol Educ. 2008;36(4):262-273. 30. Brown SDP. A process-oriented guided inquiry approach to teaching medicinal chemistry. Am J Pharm Educ. 2010;74(7): Article 121.

31. Kritikos VSP, Woulfe JM, Sukkar MBP, Saini BP. Intergroup peer assessment in problem-based learning tutorials for undergraduate pharmacy students. Am J Pharm Educ. 2011;75(4): Article 73.

32. Ferreri SPP, O'Connor SKP. Redesign of a large lecture course into a small-group learning course. Am J Pharm Educ. 2013;77(1): Article 13.

33. Willis SC, Jones A, Bundy C, Burdett K, Whitehouse CR,

O'Neill PA. Small-group work and assessment in a pbl curriculum: a qualitative and quantitative evaluation of student perceptions of the process of working in small groups and its assessment. Med Teach. 2002;24(5):495-501.

34. Eva KW. Assessing tutorial-based assessment. Advances in Health Sciences Education. 2001;6(3):243-257.

35. Papinczak T, Young L, Groves M. Peer assessment in problembased learning: a qualitative study. Advances in Health Sciences Education. 2007;12(2):169-186.

36. Duffield KE, Spencer JA. A survey of medical students' views about the purposes and fairness of assessment. Med Educ. 2002;36(9):879-886.

37. Nicol DJ, Macfarlane-Dick D. Formative assessment and selfregulated learning: a model and seven principles of good feedback practice. Studies in Higher Education. 2006;31(2):199-218.

38. Papinczak T, Young L, Groves M, Haynes M. An analysis of peer, self, and tutor assessment in problem-based learning tutorials. Med Teach. 2007;29(5):e122-e132.

39. Topping KJ, Smith EF, Swanson I, Elliot A. Formative peer assessment of academic writing between postgraduate students. Assessment \& Evaluation in Higher Education.

2000;25(2):149-169.

40. Mete S, Yildirim Sari H. Nursing students' expectations from tutors in pbl and effects of tutors' behaviour on nursing students. Nurse Educ Today. 2008;28(4):434-442.

41. Lewis A, Menezes D, McDermott H, et al. A comparison of course-related stressors in undergraduate problem-based learning (pbl) versus non-pbl medical programmes. BMC Med Educ. 2009;9(1):60.

42. Azer SA. Interactions between students and tutor in problembased learning: The significance of deep learning. The Kaohsiung Journal of Medical Sciences. 2009;25(5):240-249. 


\section{American Journal of Pharmaceutical Education 2019; 83 (3) Article 6597.}

43. Chan LC. The role of a pbl tutor: a personal perspective. The Kaohsiung Journal of Medical Sciences. 2008;24(3):S34-S38. 44. Ates O, Eryilmaz A. Factors affecting performance of tutors during problem-based learning implementations. Procedia - Social and Behavioral Sciences. 2010;2(2):2325-2329.

45. Boyle JT, Nicol DJ. Using classroom communication systems to support interaction and discussion in large class settings. Association for Learning Technology Journal. 2003;11(3):43-57.

46. Nicol DJ, Boyle JT. Peer instruction versus class-wide

discussion in large classes: a comparison of two interaction methods in the wired classroom. Studies in Higher Education.

2003;28(4):457-473.

47. Williams JC, Paltridge DJ. What we think we know about the tutor in problem-based learning. Health Professions Education. 2016; Article in press.

48. AlHoqail IA, Badr FM. Objective structured brainstorming questions (osbqs) in pbl tutorial sessions: Evidence based pilot study. International Journal of Health Sciences.

2010;4(2):93-102.

49. Wetzel MS. Developing the role of the tutor/facilitator. Postgrad Med J. 1996;72(850):474-477.
50. Daniels FM, Fakude LP, Linda NS, Marie Modeste RR. Nurse educators' experiences of case-based education in a South African nursing programme. Curationis. 2015;38(2):1523.

51. Turan S, Elcin M, Odabası O, Ward K, Sayek I. Evaluating the role of tutors in problem-based learning sessions. Procedia - Social and Behavioral Sciences. 2009;1(1):5-8.

52. Mauffette-Leenders LA, Erskine JA, Meenders MR. Learning with Cases. 4th ed: London, Ont.: Richard Ivey School of Business, University of Western Ontario; 2007.

53. Spark MJ, Malone DT, Maynard G, Stupans I. Cases in teaching and assessment in pharmacy education: Guidelines for assigning difficulty. Curr Pharm Teach Learn. 2016;8(5):722-725.

54. Dijken PCV, Thévoz S, Jucker-Kupper P, Feihl F, Bonvin R, Waeber B. Evaluation of an online, case-based interactive approach to teaching pathophysiology. Med Teach. 2008;30(5):e131-e136.

55. Bouhuijs P. Implementing problem-based learning: Why is it so hard? Revista de Docencia Universitaria. 2011;9(1):17-24.

56. Kaddoura MA. Critical thinking skills of nursing students in lecture-based teaching and case-based learning. International Journal for the Scholarship of Teaching and Learning. 2011;5(No 2): Article 20.

\section{Appendix 1. Topic Guide for Interview with Educators}

1. What is Case-Based Learning (CBL)?

2. Definition/explanation of CBL provided at this point: CBL uses "real life" problems that are mostly clinically-based to develop skills such as analytical thinking and reflective judgment. It often occurs in small groups in tutorials, but may also be done individually or in larger classes such as lectures. ${ }^{56}$

3. What is CBL useful for and why?

4. Do you feel CBL enhances student learning? If so, why? If not, why?

5. Do you think CBL is only useful for clinical topics or also for science-based and non-clinical topics? Kindly elaborate.

6. What are the key characteristics of effective and engaging CBL? Explain why you think these are critical characteristics?

7. Additional prompt: Is it sufficient to use tutors who are trained or should the tutor/lecturer be the content-expert?

8. Have you used case-based learning yourself? If so, please describe your use of CBL and its key attributes including its integration in your course curriculum.

9. Give an example of a case-based learning scenario you know has worked really well in a context with which you are familiar.

10. If you have not used CBL yourself before, please outline in some detail how you would go about designing and developing $\mathrm{CBL}$, and integrating it in your teaching

11. What are the challenges in implementing or conducting CBL sessions in the BPharm curriculum?

12. In what year should CBL be implemented? 